\title{
Correction: ZHX2 drives cell growth and migration via activating MEK/ERK signal and induces Sunitinib resistance by regulating the autophagy in clear cell Renal Cell Carcinoma
}

Liangsong Zhu, Rong Ding, Hao Yan, Jin Zhang and Zongming Lin

Correction to: Cell Death and Disease

https://doi.org/10.1038/s41419-020-2541-x

published online 07 May 2020
The original version of this article unfortunately contained a mistake in Fig. 5. The correct figure can be found below. The authors apologize for the error.

Published online: 14 April 2021 


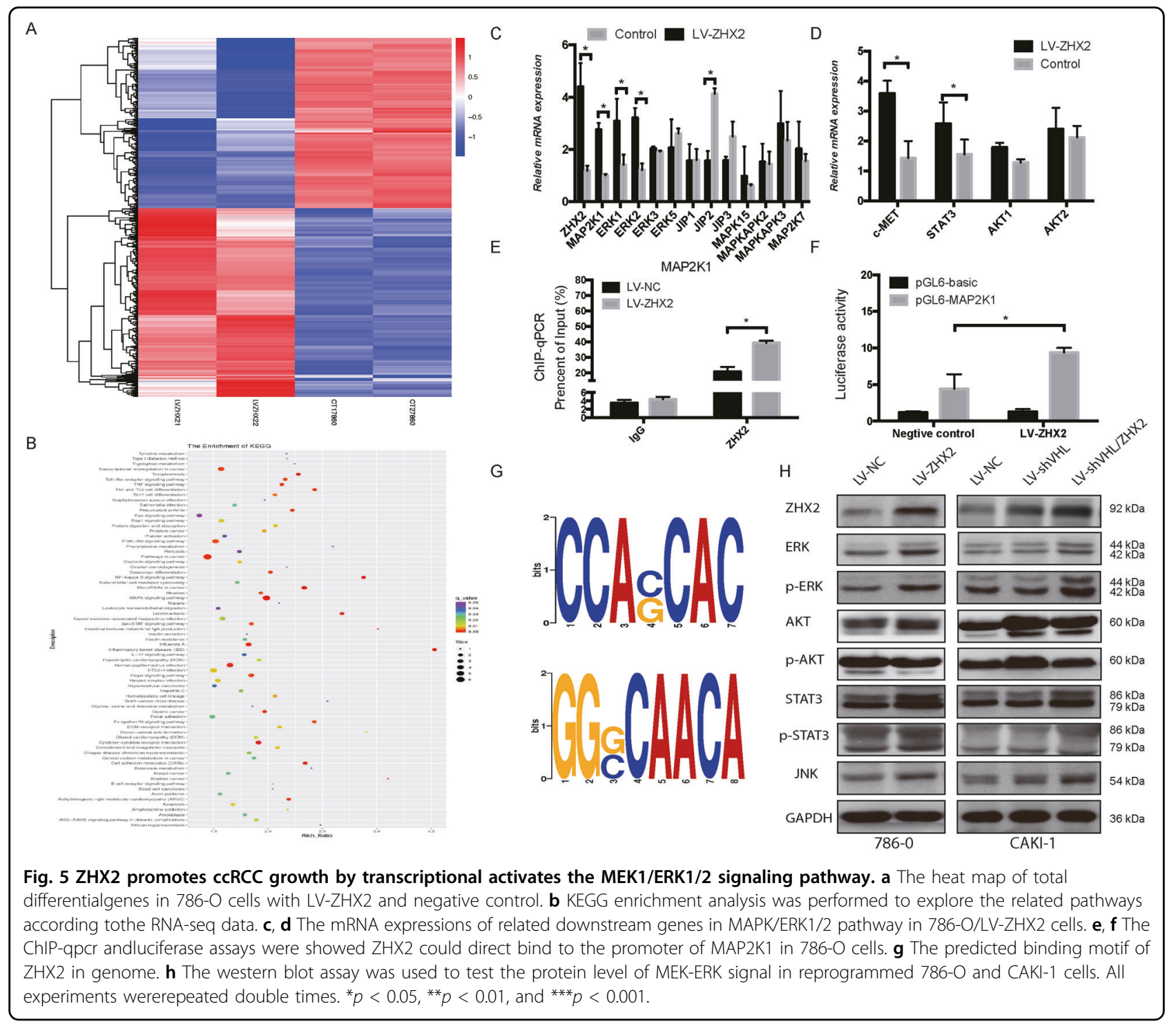

